\title{
Lethal intercostal artery injury after a fall
}

\author{
Ching-Yi Shen ${ }^{1}$, Chien-Han Hsiao ${ }^{2} \wedge$, Weide Tsai ${ }^{1,3,4}$, Ding-Kuo Chien ${ }^{1,3,4}$, Wen-Han Chang ${ }^{1,3,4}$, \\ Tse-Hao Chen ${ }^{1 \wedge}$
}

${ }^{1}$ Department of Emergency Medicine, Mackay Memorial Hospital, Taipei; ${ }^{2}$ Department of Linguistics, Indiana University, Bloomington, IN, USA; ${ }^{3}$ Department of Medicine, Mackay Medical College, New Taipei City; ${ }^{4}$ MacKay Junior College of Medicine, Nursing, and Management, Taipei

Correspondence to: Tse-Hao Chen. No. 92, Sec. 2, Zhongshan N. Rd., Taipei City 10449. Email: $99311121 @$ gms.tcu.edu.tw.

Submitted Oct 25, 2021. Accepted for publication Dec 02, 2021.

doi: 10.21037/qims-21-1041

View this article at: https://dx.doi.org/10.21037/qims-21-1041

\section{Introduction}

Intercostal artery (ICA) injury is an uncommon condition that can lead to lethal outcomes. Trauma has been identified as the main cause of ICA hemorrhage. Various treatment options for ICA hemorrhage are available, while they often require multidisciplinary collaborations. In this report, we will discuss a rare case of ICA injury resulted from a fracture of the thoracic vertebral body.

\section{Case presentation}

An 80-year-old man was brought to the emergency department (ED) due to severe middle back pain. The patient slipped in the bathroom and hit his back 1 hour prior to ED arrival. His medical history included hypertension and left renal stone. Upon presentation, the patient was alert and oriented, with a body temperature of $35.7^{\circ} \mathrm{C}$, a heart rate of 53 beats per minute, and a blood pressure of $72 / 51 \mathrm{mmHg}$. After the immediate administration of fluid resuscitation with $1,000 \mathrm{~mL}$ of normal saline, his blood pressure was elevated to $91 / 53 \mathrm{mmHg}$. Laboratory examinations revealed a Hemoglobin level of $9.5 \mathrm{~g} / \mathrm{dL}$ without the signs of leukocytosis or coagulopathy. Chest $\mathrm{X}$-ray showed a massive right pleural effusion (Figure 1A). Focused abdominal sonography for trauma manifested no ascites accumulation at the abdomen region. To determine the cause of the right pleural effusion, we conducted contrast enhanced trauma computer tomography (CT).
The trauma CT revealed a fracture of the ninth thoracic vertebra body, which resulted in a bone fragment injury of the right ICA. Extravasation of contrast media at the ICA was detected, suggesting the cause of the right hemothorax (Figure 1B-1D). Upon consultation with a chest surgeon, we began the preparation for an emergent ICA ligation, before which a cardiac arrest occurred despite the fluid resuscitation. We performed resuscitative thoracotomy at the ED. However, the patient expired eventually.

All procedures performed in this study involving human participants were in accordance with the ethical standards of the institutional and/or national research committee(s) and with the Helsinki Declaration (as revised in 2013). Ethical approval was granted from the hospital's ethics committee (No. 21MMHIS028e). Written informed consent was obtained from the patient for publication of this case report and accompanying images. A copy of the written consent is available for review by the editorial office of this journal.

\section{Discussion}

To our knowledge, only very few cases of ICA injury resulted from vertebral fracture were previously reported (1-3). ICA injury is a rare but potentially life-threatening condition. Clinical presentations of ICA injury include chest pain, dyspnea, hypotension, and increased pleural fluid $(4,5)$. Three main causes of ICA injury have been identifiedspontaneous, traumatic, and iatrogenic $(6,7)$. Spontaneous ICA hemorrhage is often associated with specific underlying

$\wedge$ ORCID: Tse-Hao Chen, 0000-0002-6370-7068; Ching-Yi Shen, 0000-0003-0502-280X; Chien-Han Hsiao, 0000-0003-4747-2243; Weide Tsai, 0000-0001-7859-2032. 

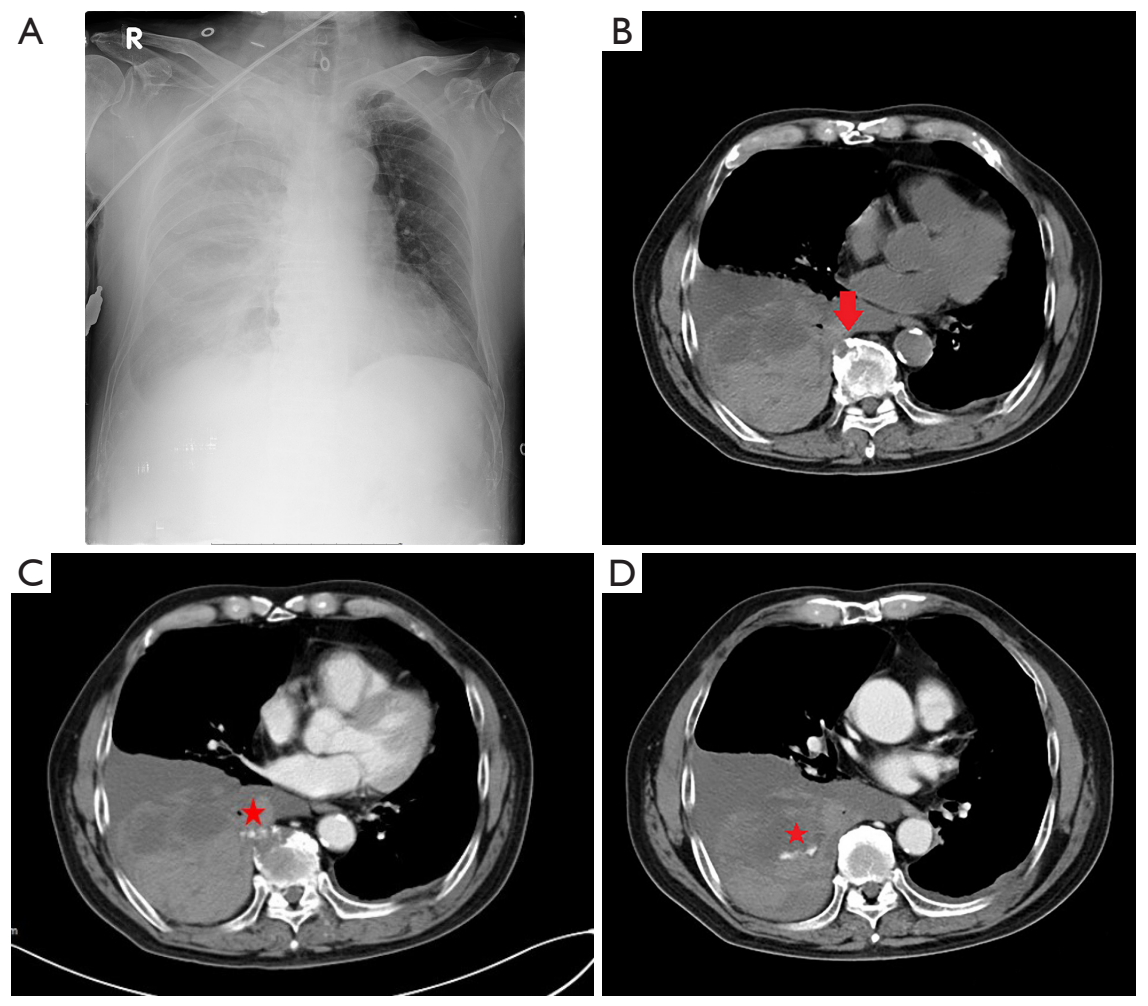

Figure 1 Image of a patient diagnosed with intercostal artery injury. (A) Chest X-ray showed a massive right pleural effusion. (B) Noncontrast CT revealed a fracture of the anterior-superior endplate of thoracic spine No. 9 body (arrow). (C,D) Contrast enhanced computed tomography (CT) manifested contrast extravasation at the right intercostal artery (star) resulted from the fractured thoracic bone fragment, which caused the right hemothorax.

diseases, such as neurofibromatosis type 1, systemic lupus erythematosus, and coagulopathy (7-9). Although extremely rare, spontaneous ruptured ICA resulted from cirrhosis or aneurysm has also been reported (5,10-12). Trauma, the most common cause of ICA hemorrhage, can be caused by either blunt or penetrating thoracic injury $(4,7,9)$. Iatrogenic causes of ICA injury include the complications with thoracentesis, pleural biopsy, chest tube insertion, and liver biopsy $(4,7)$.

Chest film and ultrasound are the common initial diagnostic tools for the detection of pleural effusion (4). The use of lung ultrasound can aid the diagnosis of patients under the suspicion of hemothorax. Previous studies revealed that lung sonography possesses a $95 \%$ positive predictive value and $92 \%$ negative predictive value for the detection of hemothorax. Clinicians should be aware of the possibility of massive hemothorax if lung ultrasound manifests increased pleural effusion or hematocrit sign $(13,14)$. However, contrast-enhanced CT remains the golden standard in the diagnosis of ICA hemorrhage $(6,15)$ because it is able to reveal detailed information, such as the source of active bleeding, the hematoma size, and other bleeding origins if any (6).

Treatment options of ICA injury include conservative management, embolization, and surgery $(6,16)$. Conservative therapy includes fluid resuscitation, chest tube drainage, pain control, and observation. In these cases, when hemodynamic instability occurs, the surgical intervention of ICA ligation should be further arranged $(6,16)$. Recently, transarterial embolization (TAE) has become an alternative treatment for patients with ICA hemorrhage $(4,6,8,10,11,15,16)$. TAE in the patients with ICA hemorrhage has been reported with a success rate of over $80 \%$ with only minor complications (6). However, emergent thoracotomy shall not be delayed when massive hemothorax with persistent bleeding is encountered (4).

\section{Acknowledgments}

Funding: None. 


\section{Footnote}

Conflicts of Interest: All authors have completed the ICMJE uniform disclosure form (available at https://dx.doi. org/10.21037/qims-21-1041). The authors have no conflicts of interest to declare.

Ethical Statement: The authors are accountable for all aspects of the work in ensuring that questions related to the accuracy or integrity of any part of the work are appropriately investigated and resolved. All procedures performed in this study involving human participants were in accordance with the ethical standards of the institutional and/or national research committee(s) and with the Helsinki Declaration (as revised in 2013). Ethical approval was granted from the hospital's ethics committee (No. 21MMHIS028e). Written informed consent was obtained from the patient for publication of this case report and accompanying images. A copy of the written consent is available for review by the editorial office of this journal.

Open Access Statement: This is an Open Access article distributed in accordance with the Creative Commons Attribution-NonCommercial-NoDerivs 4.0 International License (CC BY-NC-ND 4.0), which permits the noncommercial replication and distribution of the article with the strict proviso that no changes or edits are made and the original work is properly cited (including links to both the formal publication through the relevant DOI and the license). See: https://creativecommons.org/licenses/by-nc-nd/4.0/.

\section{References}

1. Morita S, Tsuji T, Yamagiwa T, Fukushima T, Inokuchi S. Lethal hemothorax following thoracic dislocated spinal fracture: the usefulness of arterial embolization. Int J Emerg Med 2009;2:177-8.

2. van Raaij TM, Slis HW, Hoogland PH, de Mol van Otterloo JC, Ulrich C. Massive haemothorax following thoracic vertebral fracture. Injury 2000;31:202-3.

3. Dalvie SS, Burwell M, Noordeen MH. Haemothorax and thoracic spinal fracture. A case for early stabilization. Injury 2000;31:269-70.

4. Laugsand EA, Xanthoulis A. Management of a lifethreatening intercostal artery bleeding, difficult to visualize in open surgery: a case report. J Surg Case Rep 2020;2020:rjaa444.

5. Rahi MS, Pednekar P, Parmar G, Keibel L, Gunasekaran K, Amoah K, Winterbottom C. Spontaneous intercostal artery bleeding in a patient with alcohol-induced liver cirrhosis. Clin Case Rep 2021;9:e04613.

6. Stampfl U, Sommer CM, Bellemann N, Kortes N, Gnutzmann D, Mokry T, Gockner T, Schmitz A, Ott K, Kauczor HU, Radeleff B. Emergency embolization for the treatment of acute hemorrhage from intercostal arteries. Emerg Radiol 2014;21:565-70.

7. Rentenberger C, Shue J, Soffin EM, Stiles BM, Craig $\mathrm{CM}$, Hughes AP. Intercostal artery hemorrhage with hemothorax following combined lateral and posterior lumbar interbody fusion: a case report. Spinal Cord Ser Cases 2019;5:60.

8. Afonso C, Pereira J, Gil-Agostinho A, Casimiro C. Spontaneous rupture of an intercostal artery. BMJ Case Rep 2020;13:233242.

9. Moon JM, Lee SC, Chun BJ. Spontaneous intercostal artery bleeding. Emerg Med J 2008;25:53-4.

10. Aoki T, Okada A, Tsuchida M, Hayashi J. Ruptured intercostal artery pseudoaneurysm after blunt thoracic trauma. Thorac Cardiovasc Surg 2003;51:346-7.

11. Gutierrez Romero DF, Barrufet M, Lopez-Rueda A, Burrel M. Ruptured intercostal artery pseudoaneurysm in a patient with blunt thoracic trauma: diagnosis and management. BMJ Case Rep 2014;2014:bcr2013202019.

12. Junck $E$, Utarnachitt R. Ruptured intercostal artery pseudoaneurysm: a rare cause of acute back pain. BMJ Case Rep 2015;2015:bcr2015209788.

13. McEwan K, Thompson P. Ultrasound to detect haemothorax after chest injury. Emerg Med J 2007;24:581-2.

14. Ojaghi Haghighi SH, Adimi I, Shams Vahdati S, Sarkhoshi Khiavi R. Ultrasonographic diagnosis of suspected hemopneumothorax in trauma patients. Trauma Mon 2014;19:e17498.

15. Jang JY, Lim YS, Woo JH, Jang JH. Spontaneous rupture of intercostal artery after severe cough. Am J Emerg Med 2015;33:131.e1-3.

16. Chemelli AP, Thauerer M, Wiedermann F, Strasak A, Klocker J, Chemelli-Steingruber IE. Transcatheter arterial embolization for the management of iatrogenic and blunt traumatic intercostal artery injuries. J Vasc Surg 2009;49:1505-13.

Cite this article as: Shen CY, Hsiao CH, Tsai W, Chien DK, Chang WH, Chen TH. Lethal intercostal artery injury after a fall. Quant Imaging Med Surg 2022;12(3):2203-2205. doi: 10.21037/qims-21-1041 